\title{
Inheritance of the Two-points Pattern of Partly Colored Seedcoats in Common Bean
}

\author{
Mark J. Bassett \\ Department of Horticultural Sciences, Institute of Food and Agricultural Sciences, University of Florida, \\ Gainesville, FL 32611-0690
}

\begin{abstract}
AdDitional INDEX wORDs. Phaseolus vulgaris, pleiotropy, seedcoat genetics
Abstract. Common bean (Phaseolus vulgaris L.) seedcoats can have partly colored patterns such as the new two-points pattern, which has an unknown genotype. The gene $t^{\mathrm{cf}}$ (derived from PI 507984) expresses partly colored seedcoat pattern with colored flowers. A genetic tester stock tw two-points $\mathrm{BC}_{3} 5-593$ was derived from PI 507984 by backcrossing to the recurrent parent, Florida dry bean breeding line 5-593, which has black self-colored seeds and purple flowers due to the genotype $T P V$. A series of test crosses were made between $t^{\text {tf }}$ two-points $\mathrm{BC}_{3} 5-593$ and three genetic tester stocks: $t z$ ers white $\mathrm{BC}_{3} 5-593, t z$ bip bipunctata $\mathrm{BC}_{3} 5-593$, and $t z$ virgarcus $\mathrm{BC}_{3} 5-593$. All three test crosses were studied in $F_{1}$ and $F_{2}$ populations, and the latter test cross in $F_{3}$ progenies derived from 80 randomly selected $F_{2}$ plants. The two-points pattern was never observed with white flower plants expressed by $t / t$, supporting the hypothesis that $t^{\mathrm{cf}}$ is necessary for two-points expression. The complete genotype for two-points was found to be $t^{\mathrm{cf}} z j^{\mathrm{ers}}$. The $t^{\mathrm{cf}}$ gene expresses more extensive colored zones in partly colored seedcoats than $t$. For example, $t^{\mathrm{cf}} z J$ expresses self-colored seedcoats, whereas $t^{\mathrm{c} /} / t z J$ expresses white ends pattern and $t z J$ expresses virgarcus. Similarly, the $t^{\mathrm{cf}} z j^{\text {ers }}$ genotype expresses two-points pattern, whereas $t z j^{\text {ers }}$ expresses white seedcoat; and $t \mathrm{c} /-z J / j$ ers expresses PI type pattern, whereas $t z J / j^{\text {ers }}$ expresses weak virgarcus pattern.
\end{abstract}

In common bean (Phaseolus vulgaris L.), the $t$ allele of the $T$ locus expresses two pleiotropic effects, viz., partly colored seedcoats and white flowers (Leakey, 1988). The term "partly colored" denotes a seedcoat pattern, part of which is white, whereas the remainder is any nonwhite color. Bassett et al. (1999) presented data supporting the hypothesis that a second recessive allele exits at the $T$ locus with gene symbol $t^{\mathrm{cf}}$, which permits expression of colored flowers and partly colored seedcoats. The gene $t^{\mathrm{cf}}$ was derived from the Plant Introduction (PI) accession 507984, which has partly colored seedcoats that are highly sensitive to environmental conditions. The seedcoat expression can vary from self-colored to partly colored patterns that range from extensively colored to its most limited expression, the latter pattern referred to as "PI type" in this paper (Fig. 1). The development of a genetic stock, $t^{\mathrm{cf}}$ two-points $\mathrm{BC}_{3} 5-593$ is described below. When the two dots are coalesced at the micropyle, the pattern was named unipunctata by Lamprecht (1934). When the two dots are completely separate in the micropyle area, the new pattern is given the name twopoints (Fig. 2) in this paper. Lamprecht (1934) was not able to provide a genetic explanation of the unipunctata pattern, which also co-segregated with bipunctata (Fig. 3) in his material. The objectives of this research are to investigate the inheritance of the two-points pattern of partly colored seedcoats derived from PI 507984 and to compare the effects of $t^{\mathrm{cf}}$ (vs. $t$ ) on the extent of colored zones in partly colored seedcoat patterns.

\section{Materials and Methods}

DEVELOPMENT OF GENETIC TESTER STOCKS. Florida dry bean breeding line 5-593 has the black seedcoat genotype $T$ Bip $P$ [C r] Z J G B VRk (Bassett, 2003) and has been used for many years as a recurrent parent in a program to produce genetic tester

Received for publication 30 June 2004. Accepted for publication 9 Sept. 2004 Fla. Agr. Expt. Sta. Journal Series no. R-10242. I thank Hallie Smith, formerly with the Graphics Dept., Office of Instructional Resources, Univ. of Florida, Gainesville, for preparing the illustrations used in this paper.
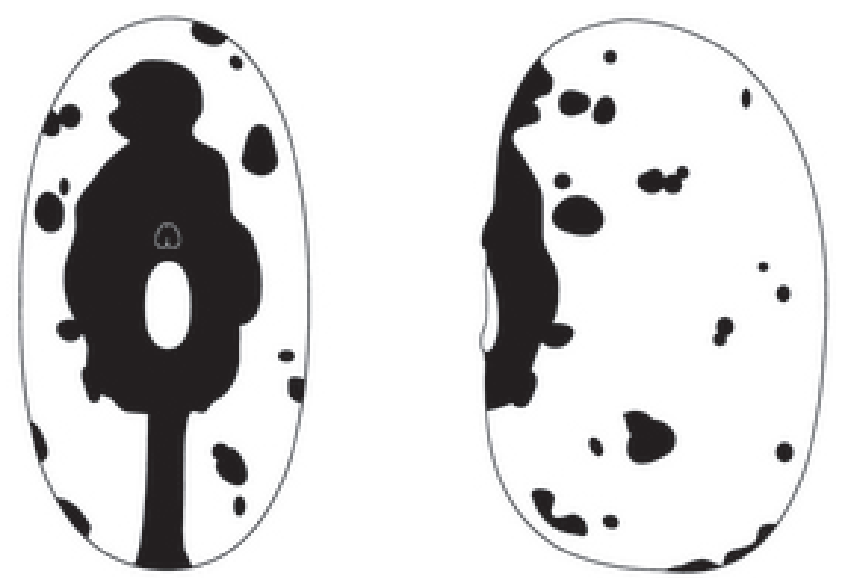

Fig. 1. A ventral view (left seed) and a side view (right seed) of PI 507984 with the "PI type" pattern of partly colored seeds of common bean typical of 1) seed grown at Pullman, Wash. or 2) expressed by genotypes $t \mathrm{t} /-z / z$ Bip/Bip J/jers when grown at Gainesville, Fla.
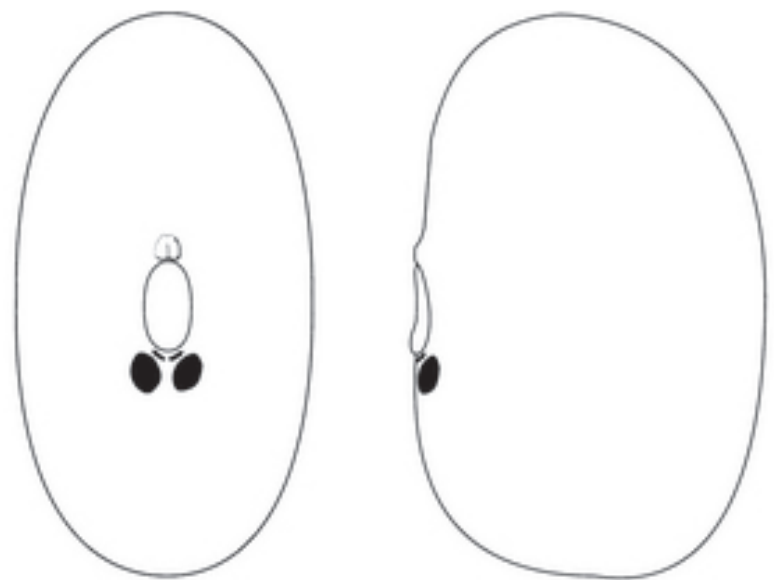

Fig. 2. A ventral view (left seed) and a side view (right seed) of the two-points pattern of partly colored seeds of common bean expressed by genotype $t^{\mathrm{cf}} z$ Bip jers. 

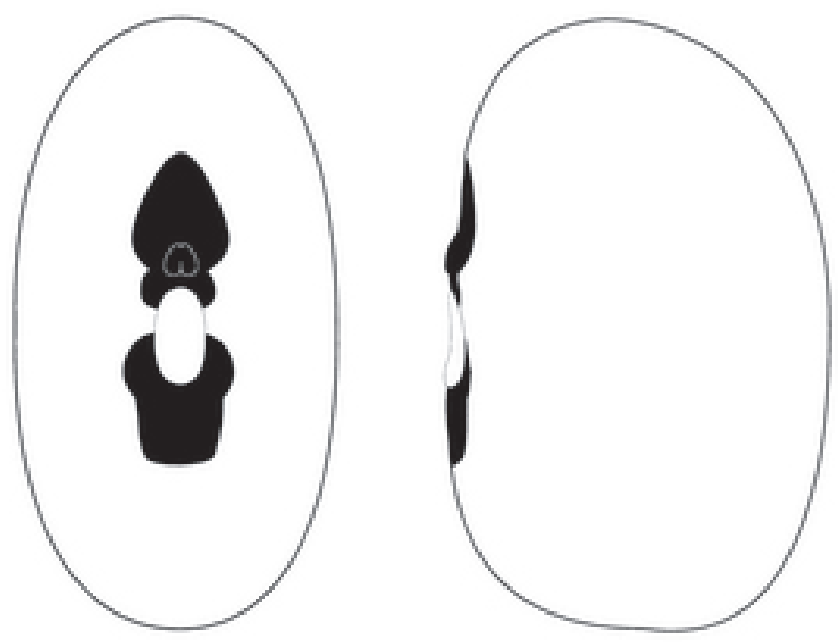

Fig. 3. A ventral view (left seed) and a side view (right seed) of the bipunctata pattern of partly colored seeds of common bean expressed by genotype $t z$ bip $J$.

stocks. These stocks contain one or more recessive marker genes backcrossed into 5-593 with selection against all other marker genes (Bassett, 1994). Line 5-593 has colored (purple) flowers due to the genotype $T P V$ (Leakey, 1988).

Development of the genetic tester stocks with the partly colored seedcoat patterns virgarcus ( $t z$ virgarcus $\mathrm{BC}_{3}$ 5-593) (Fig. 4) and bipunctata $\left(t z\right.$ bip bipunctata $\left.\mathrm{BC}_{3} 5-593\right)$ have already been described (Bassett, 1996). Similarly, development of the genetic tester stock with white seedcoats, $t z$ jers white $\mathrm{BC}_{3} 5-593$, has also been previously described (Bassett, 1997a).

PI 507984 has (under growing conditions at Pullman, Wash.) a partly colored seedcoat pattern (Fig. 1) referred to as "PI type" in this paper, but has bishops violet flowers rather than the white flowers expected with $t$. The crosses PI $507984 \times t z$ bip bipunctata $\mathrm{BC}_{3}$ 5-593 and PI $507984 \times 5-593$ were made in 1989; and data were recorded on segregation for flower color and seedcoat pattern in the $\mathrm{F}_{2}$ progenies, which were grown in the field in Spring 1990. With further inbreeding and selection from the PI 507984 $\times t z$ bip bipunctata $\mathrm{BC}_{3} 5-593$ cross, a true breeding $\mathrm{F}_{5}$ selection designated as " $\mathrm{F}_{5} t$ cf two-points bishops violet $(\mathrm{BV})$ flowers" was made in 1992. The subsequent cross $\mathrm{F}_{5} t^{\text {cf }}$ two-points BV flowers $\times 5-593$ produced the true breeding $\mathrm{F}_{3}$ selection $t^{\text {cf }}$ two-points $\mathrm{BC}_{1} 5-593$ in 1993. An additional backcross to 5-593, viz., $t^{\mathrm{cf}}$ two-points $\mathrm{BC}_{1} 5-593 \times 5-593$, produced (after inbreeding and selection) the true breeding selection $t^{\mathrm{cf}}$ two-points $\mathrm{BC}_{2} 5-593$ in 1994. Similarly, a final backcross to 5-593 created the genetic stock $t^{\text {cf }}$ two-points $\mathrm{BC}_{3}$ 5-593 in 1995 .

Crosses used in The Inheritance Study. The cross $t^{\mathrm{cf}}$ twopoints $\mathrm{BC}_{3} 5-593 \times t z j^{\text {ers }}$ white $\mathrm{BC}_{3} 5-593$ was made in the greenhouse in Fall 1996, and the $\mathrm{F}_{2}$ progeny were planted in the field in Spring 1997. Data were recorded on segregation for flower color and seedcoat pattern in $\mathrm{F}_{1}$ and $\mathrm{F}_{2}$. The crosses $t^{\mathrm{cf}}$ two-points $\mathrm{BC}_{3} 5-593 \times t z$ virgarcus $\mathrm{BC}_{3} 5-593$ and $t z$ bip bipunctata $\mathrm{BC}_{3}$ $5-593 \times t^{\mathrm{cf}}$ two-points $\mathrm{BC}_{3} 5-593$ were made in the greenhouse in Fall 1995, and the $\mathrm{F}_{2}$ progenies from both crosses were grown in the field in Spring 1996. Data were recorded on segregation for flower color and seedcoat pattern in $\mathrm{F}_{1}$ and $\mathrm{F}_{2}$.

From remnant $\mathrm{F}_{2}$ seed of the cross $t$ cf two-points $\mathrm{BC}_{3} 5-593 \times$ $t z$ virgarcus $\mathrm{BC}_{3} 5-593,80$ randomly selected plants were grown in the greenhouse in Fall 1996. The resulting $80 \mathrm{~F}_{3}$ progenies were grown in the field in Spring 1997. Data were recorded on segregation for flower color and seedcoat pattern in $\mathrm{F}_{2}$ and $\mathrm{F}_{3}$. The
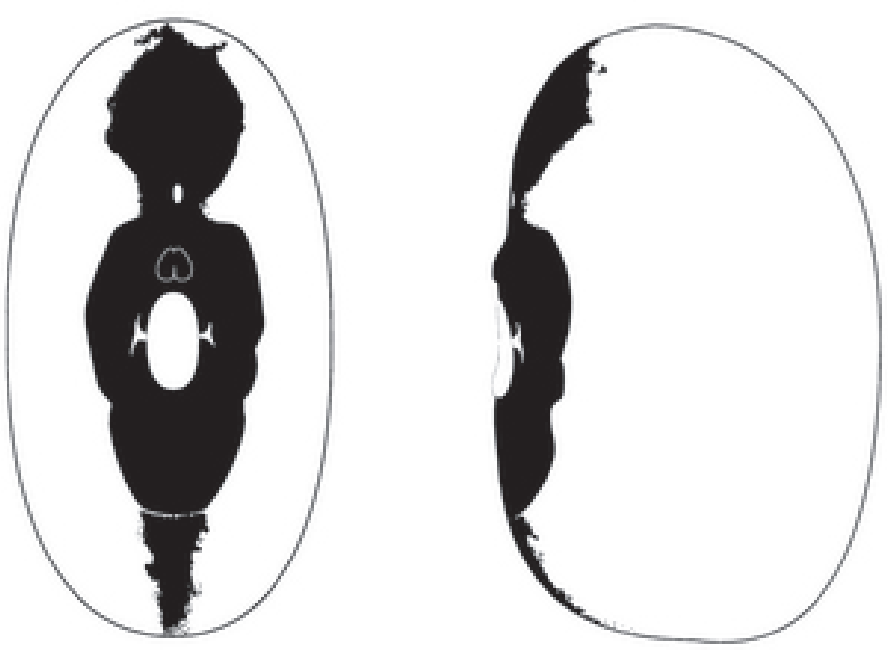

Fig. 4. A ventral view (left seed) and a side view (right seed) of the virgarcus pattern of partly colored seeds of common bean expressed by genotype $t z$ Bip J.

basis for choosing $80 \mathrm{~F}_{2}$ parents for the $\mathrm{F}_{3}$ progeny test was as follows. For the anticipated segregation for two genes ( $T$ and $J$ ), the least frequent $\mathrm{F}_{2}$ genotypes would occur at a $1 / 16$ frequency. For approximately a $95 \%$ level of probability of obtaining at least one such $\mathrm{F}_{2}$ parent, the sample size is $3 \times 16=48$. With 80 $\mathrm{F}_{2}$ parents, the probability of observing all segregation patterns is $>95 \%$.

\section{Results and Discussion}

The genetic hypothesis for the two-points seedcoat pattern is presented in advance to make the paper easier to follow (Table $1)$. Two-points can only express with $t^{\text {cf }} z j^{\text {ers }}$. The cross $t^{\text {cf }}\left(z j^{\text {ers }}\right)$ two-points $\mathrm{BC}_{3} 5-593 \times t z$ jers white $\mathrm{BC}_{3} 5-593$ was made to test the genetic hypothesis given above for two-points. The $\mathrm{F}_{1}$ progeny ( $\left.t^{\mathrm{cf}} / t z j^{\mathrm{ers}}\right)$ had nearly white seedcoats, which agrees with the expected phenotype (Table 1) for that genotype (data not shown). In terms of the genetic hypothesis for two-points, the $\mathrm{F}_{2}$ segregated only at $T$, and not at $Z$ or $J$ (Table 2). Plants with purple flowers expressed only two phenotypic classes for seedcoats: 27 two-points pattern $\left(t^{\mathrm{c} f} / t^{\mathrm{cf}} z j^{\text {ers }}\right)$ and 42 nearly white $\left(t^{\mathrm{cf}} / t z j^{\text {ers }}\right)$. Plants with white flowers and seedcoats were interpreted to have the genotype $t z$ jers, which is known to express white flowers and seedcoats (Bassett, 1997a; Bassett et al., 2002). Seedcoats with genotype $t^{\mathrm{cf}} / t z j^{\text {ers }}$ are not entirely white, but are very nearly so. The faint markings on the nearly-white seedcoat class are always clearly distinct with respect to the two-points pattern. The hypothesis is that genotype $t^{\mathrm{c}} / t$ greatly suppresses seedcoat color expression compared to $t^{\mathrm{cf}} / t^{\mathrm{cf}}$. The traces of very pale color in the hilum ring or very fine dots observed are described in the footnote to Table 1 . The gene $t^{\mathrm{ff}}$ is fully dominant for flower color, but has only a very weak dominance for seedcoat pattern with $t^{\mathrm{cf}} / t z$ jers.

Thus, the test cross (Table 2) acted as an allelism test for $z$ and $j^{\text {ers }}$, and the results confirmed the hypothesis of allelism. If $t Z$ $J$ had been present, segregation for expansa pattern would have been observed. If $t z J$ had been present, segregation for virgarcus pattern would have been observed. Thus, the $t^{\mathrm{cf}}$ two-points $\mathrm{BC}_{3}$ 5-593 parent does not carry genotype $Z$ or $J$. Although the above genetic hypothesis for two-points is consistent with the data in Table 2, the hypothesis needs further testing for confirmation.

The $\mathrm{F}_{1}$ plants from the test cross $t z(J)$ bip bipunctata $\mathrm{BC}_{3}$ $5-593 \times t^{\text {cf }}\left(z j^{\text {ers }}\right.$ Bip $)$ two-points $\mathrm{BC}_{3} 5-593$ expressed bipunctata 
Table 1. The expected genetic and phenotypic segregation for common bean seedcoat patterns in $\mathrm{F}_{2}$ and $\mathrm{F}_{3}$ (in the presence of $z / z$ ) obtained when $\mathrm{F}_{1}$ genotype $t \mathrm{c} / t \mathrm{~J} / \mathrm{j}^{\mathrm{ers}}$ is self-pollinated.

\begin{tabular}{|c|c|c|c|}
\hline \multirow[b]{2}{*}{ Genotypes } & \multirow{2}{*}{$\begin{array}{c}\text { Fre- } \\
\text { quency }\end{array}$} & \multicolumn{2}{|c|}{ Expected segregation classes } \\
\hline & & In $\mathrm{F}_{2}$ progeny & In $\mathrm{F}_{3}$ progeny \\
\hline$t^{\mathrm{cf}} / t^{\mathrm{cf}} J / J$ & 1 & Self-colored & All self-colored \\
\hline$t^{\mathrm{cf}} / t^{\mathrm{cf}} \mathrm{J} / j^{\mathrm{ers}}$ & 2 & PI type & 1 self-colored:2 PI type: 1 two-points \\
\hline$t^{\mathrm{cf}} / t^{\mathrm{cf}} j^{\mathrm{ers}} / j^{\mathrm{ers}}$ & 1 & Two-points ${ }^{z}$ & All two-points ${ }^{z}$ \\
\hline$t^{\mathrm{cf}} / t J / J$ & 2 & White ends & 1 self-colored: 2 white ends: 1 virgarcus \\
\hline$t^{\mathrm{cf}} / t J / j^{\mathrm{ers}}$ & 4 & PI type & Recapitulation of the $F_{2}$ distribution \\
\hline$t^{\mathrm{cf}} / t j^{\mathrm{ers}} / j^{\mathrm{ers}}$ & 2 & Nearly white ${ }^{z}$ & 1 two-points: 3 nearly white or white ${ }^{z}$ \\
\hline$t / t J / J$ & 1 & Virgarcus & All virgarcus \\
\hline$t / t J / j^{\text {ers }}$ & 2 & Weak virgarcus & 1 virgarcus: 2 weak virgarcus: 1 white \\
\hline$t / t j^{e r s} / j^{\text {ers }}$ & 1 & White & All white \\
\hline
\end{tabular}

Table 2. Segregation in common bean for flower color and partly colored seedcoat patterns observed in the $\mathrm{F}_{2}$ from the cross $t^{\mathrm{cf}}(z$ jers $)$ two-points $\mathrm{BC}_{3} 5-593 \times t z$ jers white $\mathrm{BC}_{3} 5-593$.

\begin{tabular}{|c|c|c|c|c|}
\hline \multicolumn{2}{|c|}{ Purple flowers $^{\mathrm{z}}$} & White flowers ${ }^{\mathrm{z}}$ & & \\
\hline$t^{\mathrm{cf}} / t^{\mathrm{cf}}$ & $t^{\mathrm{cf}} / t$ & $t / t$ & $\chi^{2}$ & \\
\hline Two-points seed & Nearly white seed & White seed & $1: 2: 1$ & $P$ \\
\hline 27 & 42 & 19 & 1.636 & 0.44 \\
\hline
\end{tabular}

${ }^{\mathrm{z}}$ For the data $69\left(t^{\mathrm{cf}} /-\right)$ and $19(t / t)$, the $\chi^{2}(3: 1)=0.546, P=0.46$.
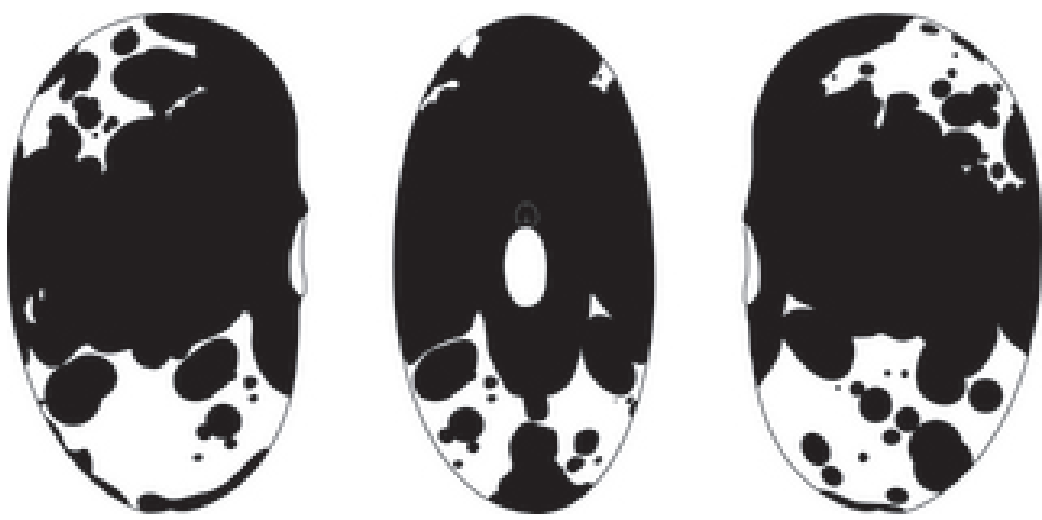

Fig. 5. A side view (left seed), a ventral view (middle seed), and the opposite side view (right seed) of the white ends pattern of partly colored seeds of common bean expressed by genotype $t^{\mathrm{cf}} / t z / z$ Bip/Bip $J / J$.

seedcoat pattern with fine dots over the remainder of the seedcoat (data not shown). The $\mathrm{F}_{2}$ segregated for plants with purple flowers and several seedcoat patterns that could not always be unambiguously classified, viz., self-colored, white ends (Fig. 5), and PI type (Table 3). Those classes were genetically interpreted as expression of $t \mathrm{cf} /-z / z \mathrm{~J} /$ - (Tables 1 and 3 ). $\mathrm{F}_{2}$ plants with white flowers $(t / t)$ also segregated for two seedcoat patterns that could not be unambiguously classified, viz., weak virgarcus (Fig. 6) and bipunctata (Table 3). The bipunctata and virgarcus classes required $t z \mathrm{~J} /$ - for expression, whereas weak virgarcus specifically required $t z J / j$ ers for expression (Bassett, 1997a; Bassett et al., 2002).

Segregation for two-points with $t / t$ white flowers was not observed, and neither was segregation for virgarcus, weak virgarcus, or bipunctata with purple flowers $\left(t^{\mathrm{cf}} / \mathrm{-}\right)$. Clearly, the partly colored seedcoat pattern virgarcus expressed by $t z J$ is permitted much greater expansion of the colored zone with genotype $t^{\text {cf }} z J$, viz., as self-colored (Tables 1 and $3)$. Similarly, the weak virgarcus pattern expressed with $t z \mathrm{~J} / \mathrm{j}^{\text {ers }}$ is permitted much greater expansion of the colored zone with genotype $t^{\mathrm{cf}} /-z_{\mathrm{J}} / \mathrm{j}$ ers , viz., as the PI type pattern. Segregation at Bip did not express a novel phenotypic class with $t$ f $/$-. The genotype for two-points pattern (with $t^{\mathrm{cf}} /$-) expressed as white seed with $t / t$. In general, $t^{\mathrm{cf}}$ permitted greater expansion of the colored zone than $t$ did for any of the genotypes at $Z, J$, and Bip that were tested. The four phenotypic classes observed gave a satisfactory fit to the expected 9:3:3:1 genetic segregation ratio for the gene combinations $t^{\mathrm{cf}} /-z \mathrm{~J} /-, t^{\mathrm{cf}} /-z j^{\mathrm{ers}} / \mathrm{j}^{\mathrm{ers}}, t / t$ $z J /-$, and $t / t z j^{\text {ers }} / j^{\text {ers }}$, respectively (Table 3 ).

The $\mathrm{F}_{1}$ plants from the test cross $t^{\mathrm{cf}}(z$ jers $)$ twopoints $\mathrm{BC}_{3} 5-593 \times t z(J)$ virgarcus $\mathrm{BC}_{3} 5-593$ expressed seedcoats with bipunctata pattern with fine dots over the remainder of the seedcoat, where the caruncula dot was much smaller than the two, large, coalesced dots at the micropyle (data not shown). The $\mathrm{F}_{2}$ segregated for the expected classes with genotype $t^{\mathrm{cf}} z \mathrm{~J} /$-, viz., self-colored, white ends and PI type (Table 4). With $t^{\text {tf }} z j^{\text {ers }}$, the expected two-points and nearly-white seed classes were observed, and the expected segregation ratio of 1 two-points $\left(t^{\mathrm{cf}} / t^{\mathrm{cf}} z j^{\mathrm{ers}}\right)$ to 2 white $\left(t^{\mathrm{cf}} / t z j^{\mathrm{ers}}\right)$ was observed. The plants with white flowers $(t / t)$ segregated for virgarcus, weak virgarcus, and white seed in a 1:2:1 ratio, respectively (Table 4 ). The segregation for all 
Table 3. Segregation in common bean for flower color and partly colored seedcoat patterns observed in the $\mathrm{F}_{2}$ from the cross $t z(J)$ bip bipunctata $\mathrm{BC}_{3} 5-593 \times t^{\mathrm{cf}}(z$ jers $B i p)$ two-points $\mathrm{BC}_{3} 5-593$.

\begin{tabular}{|c|c|c|c|c|c|}
\hline \multicolumn{2}{|c|}{ Purple flowers $t^{\mathrm{cf}} /-$} & \multicolumn{2}{|c|}{ White flowers $t / t$} & & \\
\hline $\begin{array}{l}\text { Self-colored to } \\
\text { PI type seed } \\
\mathrm{J} /-\end{array}$ & $\begin{array}{l}\text { Two-points or nearly } \\
\text { white seed } \\
j^{\text {ers }} / j^{\text {ers }}\end{array}$ & $\begin{array}{l}\text { Partly colored } \\
\text { seed }^{\mathrm{x}} \\
\mathrm{J} /-\end{array}$ & $\begin{array}{l}\text { White seed } \\
j^{\text {ers }} / j^{\text {ers }}\end{array}$ & $\chi^{2}(9: 3: 3: 1)^{\mathrm{w}}$ & $P$ \\
\hline 208 & 82 & 62 & 16 & 5.295 & 0.22 \\
\hline
\end{tabular}

${ }^{2}$ There was continuous variation from self-colored to the white ends pattern to the PI type pattern, i.e., white ends and PI type patterns were highly variable.

yThere were 30 two-points $\left(t^{\mathrm{cf}} / t^{\mathrm{cf}} z\right.$ jers $)$ and 52 nearly white $\left(t^{\mathrm{cf}} / t z j^{\text {ers }}\right)$ observations; and for the data 30 and 52 , the $\chi^{2}$ $(1: 2)=0.390, P=0.53$.

xThe classes included bipunctata, weak virgarcus, and virgarcus; unambiguous classification of the first two classes was not possible.

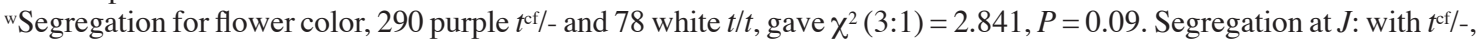
$208 \mathrm{~J} /$ - and $82 j^{\text {ers }} / j^{\text {ers }}$ gave $\chi^{2}(3: 1)=1.660, P=0.20$; and with $t / t, 62 \mathrm{~J} /$ - and $16 j^{\text {ers }} / j^{\text {ers }}$ gave $\chi^{2}(3: 1)=0.838, P=0.36$.

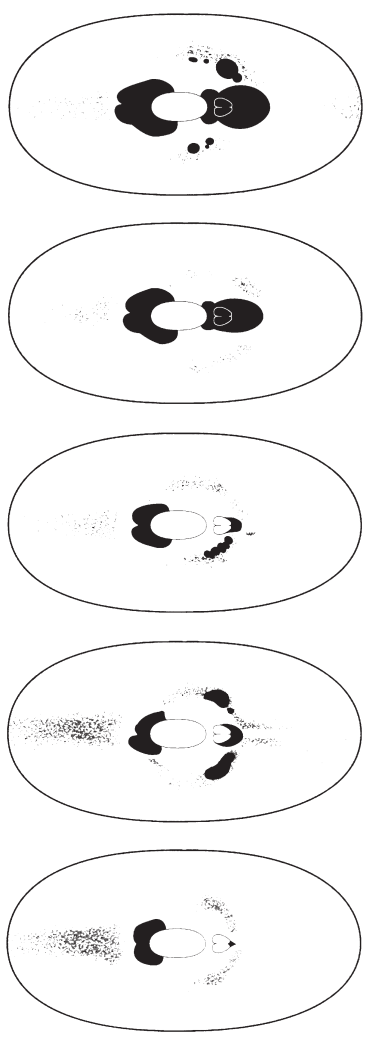

Fig. 6. Five ventral views showing the range of variability of the weak virgarcus pattern of partly colored seeds of common bean expressed by genotype $t / t \quad z / z$ Bip/Bip J/jers five phenotypic classes (or groups of classes) observed in the $\mathrm{F}_{2}$ failed to fit the expected segregation ratio 9:3:1:2:1 (Table 4). Most of the large chi-square value was due to highly disturbed segregation at $T$, viz., for $t^{\mathrm{cf}} /$ - vs. $t / t$ the $\chi^{2}(3: 1)=22.36, P<$ 0.001 . The tendency for disturbed segregation at $T$ associated with $t^{\mathrm{cf}}$ has been reported before (Bassett et al., 1999). Segregation at $J$ was normal (Table 4).

The development of $t^{\text {cf }}$ two-points $\mathrm{BC}_{3} 5-593$ began with the cross PI $507984 \times t z$ bip bipunctata $\mathrm{BC}_{3} 5$ 593 , and a question arises about a possible role for the bip gene in twopoints expression. If two-points $\mathrm{BC}_{3}$ 5-593 carried bip, then the cross $t z$ virgarcus $\mathrm{BC}_{3} 5-593 \times t^{\text {cf }}$ two-points $\mathrm{BC}_{3}$ 5-593 should segregate in $\mathrm{F}_{2}$ for bipuntata pattern seeds with genotype $t / t$. The bipunctata pattern was not observed with $t / t$ (Table 4); and, therefore, $t^{\mathrm{cf}}$ two-points $\mathrm{BC}_{3}$ 5-593 does not have genotype bip.

The 80 randomly selected $\mathrm{F}_{2}$ progeny from the cross $t^{\mathrm{cf}}\left(z j^{\mathrm{ers}}\right)$ two-points $\mathrm{BC}_{3} 5-593 \times t z(J)$ virgarcus $\mathrm{BC}_{3} 5-$ 593 segregated into five phenotypic classes (Table 5). Each of the five classes had a unique segregation pattern in $\mathrm{F}_{3}$ progeny except for the PI type class, which had two different segregation patterns (Table 5). Thus, a total of six unique segregation patterns was observed. Hypothetical genotypes were assigned to the six classes based on the model in Table 1 and the segregation data presented above for other test crosses. The four $\mathrm{F}_{2}$ parents with self-colored seedcoat $\left(t^{\mathrm{cf}} / t^{\mathrm{cf}} J / J\right)$ were true breeding in $\mathrm{F}_{3}$. One of the PI type classes ( $\left.t^{\mathrm{cf}} / t^{\mathrm{cf}} J / \mathrm{j}^{\mathrm{ers}}\right)$ segregated for only two classes (self-colored or PI type vs. two-points) with disturbed segregation at $J$. The other PI type class $\left(t^{\mathrm{cf}} / t \mathrm{~J} / \mathrm{j}^{\mathrm{ers}}\right)$ recapitulated the $\mathrm{F}_{2}$ segregation pattern of five phenotypic classes. For the second PI type class, there was disturbed segregation at $T\left(\chi^{2}\right.$
$(3: 1)=5.504, P=0.019)$ and disturbed segregation at $J$ for the $t^{\mathrm{cf} /}$ - plants $\left(\chi^{2}(3: 1)=4.301, P=0.038\right)$ but not for the $t / t$ plants $\left(\chi^{2}(1: 2: 1)=2.260, P=0.32\right)$ (Table 5). Disturbed segregation at $T$, when $t^{\text {tf }}$ was involved, was previously reported (Bassett et al., 1999). Disturbed segregation at $J$ (vs. $j^{\text {ers }}$ ), involving a surplus of

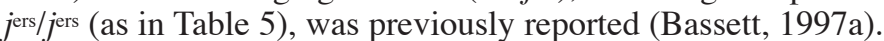
The seedcoat pattern class white ends $\left(t^{\mathrm{cf}} / t J / J\right)$ always segregated for two classes, which fit the expected 3:1 segregation ratio for 3 self-colored or white ends to 1 virgarcus, respectively. The $\mathrm{F}_{2}$ parents with two-points pattern $\left(t^{\mathrm{c} /} / t^{\mathrm{cf}} j^{\mathrm{ers}} / j^{\mathrm{ers}}\right)$ were always true breeding in $\mathrm{F}_{3}$, whereas the $\mathrm{F}_{2}$ parents with nearly white seedcoats ( $\left.t^{\mathrm{c} f} / t \mathrm{j}^{\mathrm{ers}} / j^{\mathrm{ers}}\right)$ always segregated 3:1 for $t^{\mathrm{cf} /}$ - two-points or nearly white to $t / t$ white seed, respectively (Table 5). The frequency of the six classes of $\mathrm{F}_{2}$ plants fit the expected ratio of $1: 2: 1: 2: 4: 2$ for their respective genotypes and expected $\mathrm{F}_{3}$ segregation patterns (Table 5). The above results strongly support the genetic hypothesis for the two-points pattern (Table 1). Thus, the genotype $t^{\mathrm{cf}} z$ $j^{\text {ers }}$ for two-points pattern was confirmed.

The $\mathrm{F}_{2}$ plants with PItype seedcoat pattern were always expressions of heterozygosity at $J$ (Table 5), whereas when PI 507984 is grown at Pullman, Wash., the PI type pattern is true breeding (due to a homozygous genotype). The author's hypothesis is that the PI type pattern of PI 507984 has a different genotype at the $Z$ locus compared with the heterozygous PI type materials presented in Table 5 . The cross PI $507984 \times t z$ bip bipunctata $\mathrm{BC}_{3}$ 5-593 segregated in $\mathrm{F}_{2}$ (111 total progeny) for partly colored seedcoat patterns (Bassett, 1996, 1997b) known to require either $Z$ (self-colored, expansa or ambigua, 34 plants) or $z^{\text {sel }}$ (sellatus, 21 plants) for their expression (data not shown). The cross PI $507984 \times 5-593$ segregated in $\mathrm{F}_{2}$ (184 total progeny) for only eight partly colored progeny, which were all of the expansa class. From the first cross, plants with white flowers $(t / t)$ did not segregate for the expected piebald pattern (Bassett, 1997b) expressed by genotype $t / t z^{\mathrm{sel} /} / z J / J$ Bip/Bip (data not shown). The data were not sufficient to develop a conclusive genetic hypothesis for the genotype of PI 507984 at the $Z$ locus. On the basis of the data in Tables 2 through 5, we can conclude that PI 507984 would express two-points pattern if it carried $z$, which conclusively rules out that genotype. The genotype at the $Z$ locus in PI 507984 remains uncertain. Future experimental work should be done to determine the seedcoat pattern expression of genotype $t^{\mathrm{cf}} z^{\text {sel }} j^{\text {ers }}$, which is the more plausible candidate genotype (vs. $t^{\text {cf }} Z j^{\text {ers }}$ ) for the true breeding PI type pattern. Alternatively, PI 507984 may have a novel allele at $Z$, one which has not been reported. 
Table 4. Segregation in common bean for flower color and partly colored seedcoat patterns observed in the $\mathrm{F}_{2}$ from the cross $t z(J)$ virgarcus $\mathrm{BC}_{3} 5-593 \times t^{\mathrm{cf}}(z$ jers $)$ two-points $\mathrm{BC}_{3} 5-593$.

\begin{tabular}{|c|c|c|c|c|c|c|}
\hline \multicolumn{2}{|c|}{ Purple flowers $\left(t^{\mathrm{cf}} /-\right)^{\mathrm{Z}}$} & \multicolumn{3}{|c|}{ White flowers $(t / t)^{\mathrm{z}}$} & & \\
\hline $\begin{array}{l}\text { Self-colored to } \\
\text { PI type } \\
\text { seed }^{\mathrm{y}} \\
\mathrm{J} /-\end{array}$ & $\begin{array}{l}\text { Two-points or nearly } \\
\text { white seed } \\
j^{\text {ers }} / j^{\text {ers }}\end{array}$ & $\begin{array}{l}\text { Virgarcus } \\
\text { seed } \\
J / J\end{array}$ & $\begin{array}{c}\text { Weak } \\
\text { virgarcus } \\
J / j^{\text {ers }}\end{array}$ & $\begin{array}{l}\text { White seed } \\
j^{\text {ers }} / j^{\text {ers }}\end{array}$ & $\begin{array}{c}\chi^{2} \\
9: 3: 1: 2: 1^{\mathrm{w}}\end{array}$ & $P$ \\
\hline 430 & 161 & 33 & 64 & 27 & 24.598 & $<0.001$ \\
\hline
\end{tabular}

${ }^{z}$ Segregation for flower color, $591 t^{\mathrm{cf} /}$ - and $124 t / t$, gave $\chi^{2}(3: 1)=22.36, P<0.001$. For the $t^{\mathrm{cf} /} /$ data, segregation at $J$ for seedcoat pattern was $430 \mathrm{~J} /$ - and $161 \mathrm{jers} / j^{\text {ers }}$, giving the $\chi^{2}(3: 1)=1.584, P=0.21$. For the $t / t$ data, segregation at $J$ for seedcoat pattern was $33 J / J, 64 J / j$ ers, and $27 j^{\text {ers }} / j^{\text {ers }}$, giving the $\chi^{2}(1: 2: 1)=0.710, P=0.70$. Thus, disturbed segregation at $T$ was entirely responsible for the failure of the model.

yThere was continuous variation from self-colored to white ends pattern to the PI type pattern.

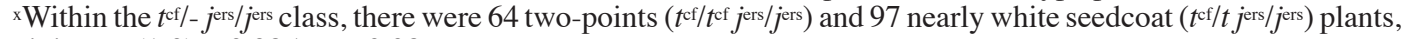
giving $\chi^{2}(1: 2)=2.985, P=0.08$.

Table 5. Segregation in common bean for flower color and seedcoat pattern observed in $\mathrm{F}_{3}$ progenies from $80 \mathrm{~F}_{2}$ parents selected for purple flowers $\left(t^{\mathrm{cf}} /-\right)$ but randomly selected for seedcoat pattern from the cross $t^{\mathrm{cf}}\left(z \mathrm{j}^{\mathrm{ers}}\right)$ two-points $\mathrm{BC}_{3} 5-593 \times t z(J)$ virgarcus $\mathrm{BC}_{3} 5-593$.

\begin{tabular}{|c|c|c|c|c|c|c|c|}
\hline \multirow[b]{3}{*}{$\begin{array}{l}\text { Class } \\
\text { no. }\end{array}$} & \multirow[b]{3}{*}{$\begin{array}{l}\mathrm{F}_{2} \text { parents, } \\
\text { phenotypes and } \\
\text { genotypes }^{\mathrm{z}}\end{array}$} & \multirow[b]{3}{*}{$\begin{array}{l}\text { No. of } \\
\mathrm{F}_{3} \text { plots }\end{array}$} & \multicolumn{5}{|c|}{ Segregation in $\mathrm{F}_{3}$} \\
\hline & & & \multicolumn{2}{|c|}{ Purple flowers $\left(t^{\mathrm{cf}} /-\right)$} & \multicolumn{3}{|c|}{ White flowers $(t / t)$} \\
\hline & & & $\begin{array}{c}\text { Self-colored } \\
\text { to PI type } \\
\text { seed }^{\mathrm{y}} \\
\mathrm{J} /-\end{array}$ & $\begin{array}{c}\text { Two-points } \\
\text { and nearly } \\
\text { white seed } \\
j^{\text {ers }} / j^{\text {ers }}\end{array}$ & $\begin{array}{c}\text { Virgarcus } \\
\text { seed } \\
J / J\end{array}$ & $\begin{array}{c}\text { Weak } \\
\text { virgarcus } \\
\text { seed } \\
J / j^{\text {ers }}\end{array}$ & $\begin{array}{l}\text { White seed } \\
j^{\text {ers }} / j^{\text {ers }}\end{array}$ \\
\hline 1 & $\begin{array}{c}\text { Self-colored seed } \\
t^{\mathrm{cf}} / t^{\mathrm{cf}} J / J\end{array}$ & 4 & $280^{\mathrm{x}}$ & & & & \\
\hline 2 & $\begin{array}{l}\text { PI type seed } \\
t^{\mathrm{cf}} / t^{\mathrm{cf}} J / j^{\text {ers }}\end{array}$ & 12 & 497 & 212 & & & \\
\hline 3 & $\begin{array}{c}\text { Two-points seed } \\
t^{\mathrm{cf}} / t^{\mathrm{cf}} j^{\text {ers }} / j^{\text {ers }}\end{array}$ & 12 & & $538^{\mathrm{x}}$ & & & \\
\hline 4 & $\begin{array}{l}\text { White ends seed } \\
t^{\mathrm{cf}} / t J / J\end{array}$ & 13 & 608 & & 187 & & \\
\hline 5 & $\begin{array}{l}\text { PI type seed } \\
t^{\mathrm{cf}} / t J / j^{\mathrm{ers}}\end{array}$ & 30 & 995 & 376 & 105 & 208 & 87 \\
\hline 6 & $\begin{array}{l}\text { Nearly white seed } \\
t^{\text {cf }} / t j^{\text {ers }} / j^{\text {ers }}\end{array}$ & 9 & & 310 & & & 124 \\
\hline
\end{tabular}

zFor the observed class frequencies $4,12,12,13,30,9$, the $\chi^{2}(1: 2: 1: 2: 4: 2)=7.30, P=0.20$.

yThree seedcoat classes were combined: self-colored seeds, white ends, and PI type.

${ }^{x} \mathrm{All}_{3}$ plots were true breeding only for the indicated seedcoat phenotype of the $\mathrm{F}_{2}$ parent.

wThose PI type (Fig. 1) $\mathrm{F}_{3}$ progenies segregated for two classes: 1) self-colored or PI type, and 2) two-points. For the data 497 and $212\left(\mathrm{~J} /\right.$ - vs. $\left.j^{\text {ers }} / j^{\text {ers }}\right)$, the $\chi^{2}(3: 1)=9.084, P=0.003$ and $\chi^{2}(9: 7)=55.25, P=0.001$.

'White ends (Fig. 5) segregated for two classes: 1) self-colored or white ends, and 2) virgarcus. For the data 608 and 187 , the $\chi^{2}(3: 1)=0.926, P=0.34$.

uThose $\mathrm{F}_{3}$ progenies recapitulated the $\mathrm{F}_{2}$ segregation. For the data $995,376,105,208$, and 87 , the $\chi^{2}(9: 3: 1: 2: 1)=$ $11.98, P=0.017$. For the data 995 and $376\left(J /-\right.$ vs. $j^{\text {ers }} /$ jers $)$, the $\chi^{2}(3: 1)=4.301, P=0.038$. For the data 105,208 , and 87 , the $\chi^{2}(1: 2: 1)=2.260, P=0.32$. For the data 1371 and $400\left(t^{\mathrm{cf}} /-\mathrm{vs} . t / t\right)$, the $\chi^{2}(3: 1)=5.504, P=0.019$. tNearly white progenies segregated for two classes: 1) two-points or nearly white, and 2) white seed. For the data 310 and 124 , the $\chi^{2}(3: 1)=2.952, P=0.09$.

\section{Literature Cited}

Bassett, M.J. 1994. The griseoalbus (gray-white) seedcoat color is controlled by an allele ( $p$ gri $)$ at the $P$ locus in common bean. HortScience 29:1178-1179.

Bassett, M.J. 1996. Inheritance of the partly colored seedcoat pattern, bipunctata, in common bean. J. Amer. Soc. Sci. 121:1032-1034.

Bassett, M.J. 1997a. Allelism tests involving two genes, ers and ers-2, that restrict partly colored seedcoat expression in common bean. J. Amer. Soc. Hort. Sci. 122:802-807.

Bassett, M.J. 1997b. Tight linkage between the Fin locus for plant habit and the $Z$ locus for partly colored seedcoat patterns in common bean. J. Amer. Soc. Hort. Sci. 122:656-658.

Bassett, M.J. 2003. The seed coat color genotype of 5-593, the recurrent parent for many genetic stocks of common bean maintained as PI lines at Pullman, WA. Annu. Rpt. Bean Improvement Coop. 46:37-38.

Bassett, M.J., L. Brady, and P.E. McClean. 1999. A new allele, $t^{\mathrm{cf}}$, at the $T$ locus for partly colored seedcoats in common bean. J. Amer. Soc. Hort. Sci. 124:663-665.

Bassett, M.J., R. Lee, T. Symanietz, and P. McClean. 2002. Inheritance of reverse margo seedcoat pattern and allelism between the genes $J$ for seedcoat color and $L$ for partly colored seedcoat pattern in common bean. J. Amer. Soc. Hort. Sci. 127:56-61.

Lamprecht, H. 1940. Zur Genetik von Phaseolus vulgaris. XVI. Weitere Beiträge zur Vererbung der Teilfarbigkeit. Hereditas 26:277-291.

Leakey, C.L.A. 1988. Genotypic and phenotypic markers in common bean, p. 245-327. In: P. Gepts (ed.). Genetic resources of Phaseolus beans. Kluwer, Boston. 